\title{
PENGARUH PROMOSI DAN KUALITAS PELAYANAN TERHADAP KEPUTUSAN NASABAH MENGGUNAKAN TABUNGAN IB BAITULLAH PADA BNI SYARIAH KANTOR CABANG MEDAN
}

\section{THE EFFECT OF PROMOTION AND SERVICE QUALITY ON CUSTOMERS' DECISIONS TO USE iB BAITULLAH SACINGS AT BNI SYARIAH KANTOR CABANG MEDAN}

\author{
Hafni Zahara1a \\ 1aPoliteknik Negeri Medan, e-mail: hafnizahara7@gmail.com
}

\begin{abstract}
This research was conducted to determine the effect of promotion and service quality on using iB baitullah savings customer decision at PT BNI Syariah Medan Branch Office. The dependent variable in this study is the customer decisions using iB baitullah saving, while the independent variable consists of promotion and service quality. The use of research methods in this study is multiple linear regression analysis, partial test $(\mathrm{t})$ and simultaneous test $(\mathrm{F})$. The results of the partial test $(\mathrm{t})$ show that each independent variable has a positive and significant influence on the dependent variable. Simultaneously promotion and service quality have a positive and significant effect on iB Baitullah savings customers' decisions as seen through the $\mathrm{F}$ statistical test with a significance value amounting to $(0,000<0.05)$.
\end{abstract}

\section{ABSTRAK}

Penelitian ini dilakukan untuk mengetahui kualitas pelayanan dan pengaruh promosi terhadap keputusan nasabah memanfaatkan tabungan iB baitullah pada PT. BNI Syariah Kantor Cabang Medan. Dalam penelitian ini yang menjadi variabel dependen adalah keputusan nasabah menggunakan tabungan iB baitullah, sedangkan variabel independen terdiri dari promosi dan kualitas pelayanan. Penggunaan metode penelitian pada penelitian ini ialah analisis regresi linier berganda, uji parsial $(\mathrm{t})$ dan uji simultan (F). Hasil penelitian dengan uji parsial $(\mathrm{t})$ menunjukkan bahwa setiap variabel independen memiliki pengaruh positif dan juga signifikan terhadap variabel dependen, Secara simultan promosi serta kualitas pelayanan memiliki pengaruh yang positif dan signifikan terhadap keputusan nasabah tabungan iB baitullah yang dilihat melalui uji statistik F dengan nilai signifikansi sebesar $(0,000<0,05)$.

Kata Kunci: Promosi, Kualitas Pelayanan, Keputusan Nasabah

Hafni Zahara. 2020. Pengaruh Promosi dan Kualitas Pelayanan Terhadap Keputusan Nasabah Menggunakan Tabungan iB Baitullah pada BNI Syariah Kantor Cabang Medan. Jurnal Nisbah 6 (1): 49-55. 


\section{PENDAHULUAN}

Perbankan syariah adalah perusahaan yang bergerak di bidang jasa, namun sistem dan kegiatan usahanya berlandaskan pada hukum Islam sebagaimana ditetapkan dalam Al-Qur'an dan Hadits. Perkembangan perbankan syariah saat ini kian pesat semenjak disahkannya Undang-Undang Perbankan No. 7 tahun 1992 sebagaimana telah diubah Undang Undang No. 10 Tahun 1998 mengenai perbankan syariah dimana bank memiliki peluang tinggi dalam mengembangkan industri perbankan syariah (Yogiarto, 2015).

Salah satu produk bank yang diminati saat ini adalah produk tabungan haji karena setiap tahunnya pendaftaran sebagai calon jamaah haji semakin meningkat. Menunaikan ibadah haji bagi mayoritas orang Indonesia adalah suatu hal yang tidak mudah. Ia membuhkan keinginan yang kuat dan kapasitas yang memadai. Ada banyak orang yang telah mampu tetapi belum mempunyai kemauan, dan lebih banyak lagi yang sudah mempunyai kemauan tetapi belum memepunyai kemampuan yang cukup.

Adapun produk pada PT. BNI Syariah salah satunya yaitu tabungan iB Baitullah dimana tabungan ini menerapkan akad wadiah atau akad mudharabah yang digunakan sebagai media untuk memperoleh kepastian kouta berangkat menunaikan ibadah haji (regular/khusus) dan menyesuaikan keinginan nasabah dalam perencanaan ibadah umrah dengan skema setoran bulanan atau bebas baik dengan menggunakan mata uang rupiah maupun mata uang asing (USD) (www.bnisyariah.co.id diunduh 12 Juli 2019).

Dalam menjual produknya, bank harus mengenalkan produk kepada pelanggan yang dituju dengan cara promosi. Keputusan didapatkan setelah melihat perbandingan persepsi konsumen atas pelayanan yang diperolehnya dengan harapan konsumen terhadap pelayanan perusahaan tersebut. Pelayanan yang baik tentunya akan membawa dampak positif bagi setiap anggota maupun calon anggota, dengan begitu nasabah akan tertarik untuk memakai produk dan jasa yang ditawarkan.

Penelitian ini akan dilakukan pada PT BNI Syariah KC Medan karena pada saat melakukan observasi pra penelitian sewaktu melaksanakan praktik kerja lapangan pada bulan Maret 2019 ditemukan beberapa sumber masalah yang terlihat pada bank tersebut terkait dengan kualitas pelayanan seperti banyaknya nasabah yang tidak kebagian souvenir haji berupa buku doa dan bakal baju untuk keberangkatan haji dan keluhan karena menunggu antrian Costumer Service yang terlampau lama, juga Costumer Service yang membiarkan nasabah mengantri pada saat tidak melayani nasabah manapun.

Promosi yang dilakukan pihak bank terkait dengan tabungan iB Baitullah yang sangat minim mengingat beberapa nasabah yang tidak mengetahui fasilitas-fasilitas tabungan haji dan tidak adanya pamflet yang tertera di bank mengenai tabungan iB Baitullah.

Berdasarkan uraian di atas, maka dibentuklah suatu penelitian dengan judul "Pengaruh Promosi dan Kualitas Pelayanan terhadap Keputusan Nasabah Menggunakan Produk Tabungan iB Baitullah pada PT BNI Syariah KC Medan.

\section{MATERI DAN METODE}

Promosi merupakan salah satu elemen dari bauran pemasaran perusahaan yang diefektifkan untuk menginformasikan, mengimbau, dan mengingatkan tentang produk perusahaan tersebut. Bauran pemasaran itu sendiri diartikan sebagai 
gabungan dari personal selling atau penjualan tatap muka, promosi penjualan, dan hubungan masyarakat yang berperan bagi tercapainya tujuan perusahaan (Walker dalam Sunyoto, 2015:157).

Menurut Maksi (2010) dalam usaha perbankan yang menjadi daya tarik bagi nasabah dalam memilih suatu bank adalah kualitas pelayanan dari bank itu sendiri. Umumnya calon nasabah akan memilih bank yang mampu memberikan kemudahan dan keuntungan ketika ia menabung. Terdapat faktor-faktor yang akan menjadi bahan pertimbangan nasabah dalam mengambil keputusan untuk menabung. Mayoritas nasabah akan termotivasi untuk menggunakan produk dari yang ditawarkan oleh bank karena kualitas pelayanan yang bagus dari bank tersebut. Ketika nasabah mendapatkan pelayanan yang berkualitas maka ia akan merasa puas, hal ini sejalan dengan prinsip perilaku konsumen yaitu mencari kepuasan yang maksimal guna memenuhi kebutuhannya.

Penelitian ini menggabungkan dua jenis penelitian yaitu kuantitatif dan kualitatif. Data primer diperoleh dari diperoleh dari jawaban responden dari kuisioner yang diberikan kepada nasabah tabungan iB Baitullah pada PT BNI Syariah KC, sedangkan data sekunder diperoleh dari buku-buku, internet dan bahan acuan lainnya yang berhubungan dengan konsep penelitian yang akan dilakukan. Data yang digunakan merupakan data primer diperoleh melalui kuisioner yang disebarkan kepada 100 responden dari 60,534 jiwa. Penentuan sampel dilakukan dengan menggunakan rumus slovin.

Penelitian ini menggunakan variable independen berupa promosi (X1), dan kualitas pelayanan (X2). Juga Variabel terikat (variable dependent) dari penelitian ini adalah keputusan nasabah menggunakan tabungan iB Baitullah pada PT BNI Syariah KC Medan. Teknik analisis data adalah teknik yang digunakan untuk mengelola hasil penelitian guna memperoleh kesimpulan. Adapun pengolahan dan analisis data pada penelitian ini memanfaatkan progeam SPSS 22 dengan teknik yang digunakan adalah analisis regresi linear berganda.

\section{HASIL DAN PEMBAHASAN}

\section{Uji Asumsi Klasik Uji Normalitas}

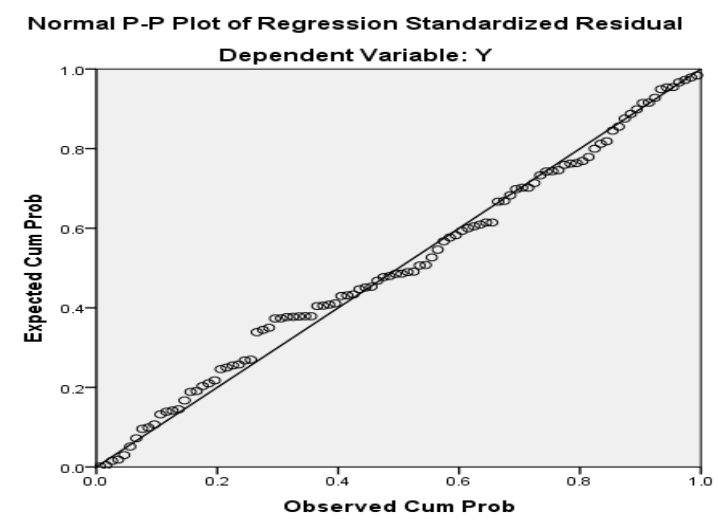

Gambar 1 Grafik P-Plot

Pada gambar 1 menunjukkan bahwa sebaran titik-titik menyebar disekitar garis diagonal dan mengikuti arah garis diagonal. Hal ini menunjukkan bahwa data residual yang digunakan dalam penelitian ini berdistribusi normal dan model regresi layak dipakai karena memenuhi asumsi klasik normalitas (Ghozali, 2016:170). 


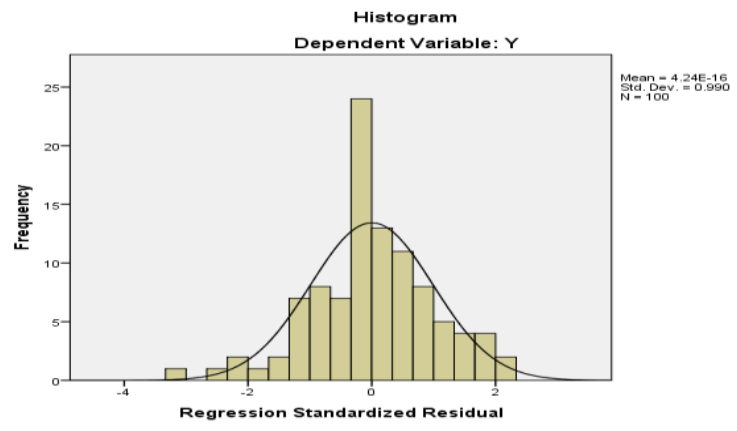

Gambar 2 Histogram

Berdasarkan gambar 4.4 dilihat bahwa perbandingan antara data observasi distribusi mendekati normal. Terlihat bahwa grafik histogram menunjukkan pola distribusi yang mendekati normal, sehingga bisa disimpulkan bahwa model regresi memenuhi asumsi normalitas.

\section{Uji Multikolinieritas}

Uji multikolinieritas bermaksud untuk menguji apakah ditemukan adanya korelasi antar variabel besba (independen) pada model regresi. Indikator baiknya model regresi ditunjukkan dengan tidak terjadi korelasi diantara variabel independen. Variabel-variabel dikatakan tidak ortogonal dikarenakan variabel independen saling berkorelasi. Untuk menguji multikolinearitas dapat dilihat dari nilai tolerance dan Variance Inflation Factor (VIF). Suatu model regresi dikatakan terbebas dari masalah multikolinearitas apabila nilai tolerance $>0,01$ atau nilai VIF $<10$ (Ghozali, 2016:105).

\section{Uji Heteroskedastisitas}

Uji heteroskedastisitas memiliki tujuan untuk menguji apakah terjadi ketidaksamaan variance dalam model regresi dari residual satu pengamatan ke pengamatan yang lain. Pengujian heteroskedastisitas dilakukan berdasarkan analisi grafik scatterplot. Indikasi telah terjadinya heteroskedastusitas ditandai dengan adanya pola tertentu, yaitu titiktitik yang ada membentuk suatu pola tertentu secara teratur (bergelombang, melebar, lalu menyempit. Namun, apabila tidak ada kejelasan pada pola, dan titik-titik menyebar pada sumbu Y di bawah angka 0 , maka tidak terjadi heteroskedastisitas (Ghozali, 2016: 13).

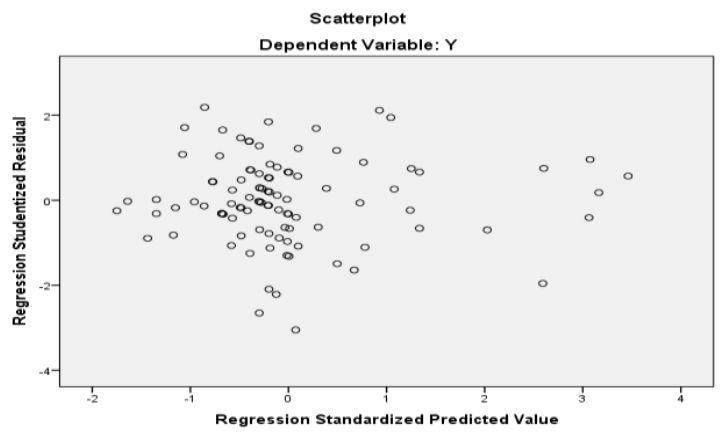

Gambar 3

Scatterplot Uji Heteroskedastisitas

Berdasarkan output scatterplot diatas, terlihat bahwa titik-titik menyebar secara random dan tersebar baik dibawah maupun diatas angka nol pada sumbu $\mathrm{Y}$ dan tak membentuk pola tertentu dengan jelas. Hal ini menunjukkan bahwa tidak terjadi masalah heteroskedastisitas pada model regresi atau data bersifat homoskedastisitas, sehingga model regresi layak digunakan untuk menganalisis promosi dan kualitas pelayanan terhadap keputusan nasabah menggunakan tabungan iB Baitullah.

\section{Hasil Analisis Regresi Linier Berganda}

Berdasarkan hasil pengumpulan dan pengolahan data diketahui promosi dan kualitas pelayanan memiliki hubungan yang positif terhadap keputusan nasabah PT BNI Syariah Kantor Cabang Medan. Hal ini ditunjukkan oleh persamaan regresi sebagai berikut: 
Tabel 1

Analisis Regresi Linier Berganda

\begin{tabular}{|c|c|}
\hline Model & B \\
\hline (Constant) & 0,955 \\
\hline Promosi & 0,298 \\
\hline Kualitas Pelayanan & 0,283 \\
\hline
\end{tabular}

Berdasarkan hasil analisis regresi linier berganda pada tabel, maka dapat ditulis persamaan regresinya:

Keputusan nasabah $=0,955+0,298$ Promosi

$+0,283$ Kualitas pelayanan

Dari rumus regresi di atas dapat dinyatakan nilai koefisien regresinya sebagai berikut:

1) Nilai konstanta sebesar 0,955 menyatakan bahwa jika tidak ada nilai promosi dan kualitas pelayanan maka besarnya keputusan nasabah sebesar 0,955 .

2) Apabila nilai promosi mengalami peningkatan sebesar 1 (satu) maka nilai keputusan nasabah akan mengalami peningkatan sebesar 0,298.

3) Apabila nilai kualitas pelayanan mengalami peningkatan sebesar 1 (satu) maka nilai keputusan nasabah akan mengalami peningkatan sebesar 0,283 .

\section{Uji t (Parsial)}

Berdasarkan hasil pengolahan uji statistik t tersebut, maka pembahasannya: Apabila tingkat signifikansi lebih kecil dari 0,05 dan thitung lebih besar dari tabel, maka variabel independen (bebas) berpengaruh terhadap variabel dependen (terikat). Berdasarkan hasil penelitian ini diperoleh tingkat signifikansi variabel untuk promosi sebesar 0,001 yang artinya lebih kecil dari

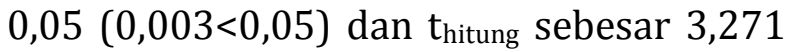
lebih besar dibandingkan dengan $t_{\text {tabel }}$ $1,985(3,271>1,985)$, maka dapat dikatakan bahwa variabel promosi berpengaruh signifikan terhadap keputusan nasabah menggunakan tabungan iB baitullah pada PT BNI Syariah KC Medan.

Uji F

Uji simultan (uji F) pada prinsipnya bertujuan untuk mengetahui pengaruh dari dua variabel independen atau lebih secara simultan (bersama-sama) terhadap variabel dependen. Berdasarkan hasil uji signifikan keseluruhan dari regresi sampel (Uji Statistik F) dapat dilihat bahwa tingkat signifikansinya sebesar 0,000 lebih kecil dari $0,05(0,000<0,05)$ dan $F_{\text {hitung }}$ sebesar 47,380 lebih besar dibandingkan dengan Ftabel 3,09 $(47,380>3,09)$, hal tersebut sesuai dengan hipotesis bahwa promosi dan kualitas pelayanan berpengaruh signifikan terhadap keputusan nasabah menggunakan tabungan iB baitullah pada PT BNI Syariah KC Medan. Maka pertanyaan rumusan masalah penelitian yang ketiga telah terjawab yaitu promosi dan kualitas pelayanan berpengaruh terhadap keputusan nasabah menggunakan tabungan iB Baitullah pada PT BNI Syariah KC Medan.

\section{Koefisien Determinasi}

Tabel 2

Koefisien Korelasi dan Koefisien

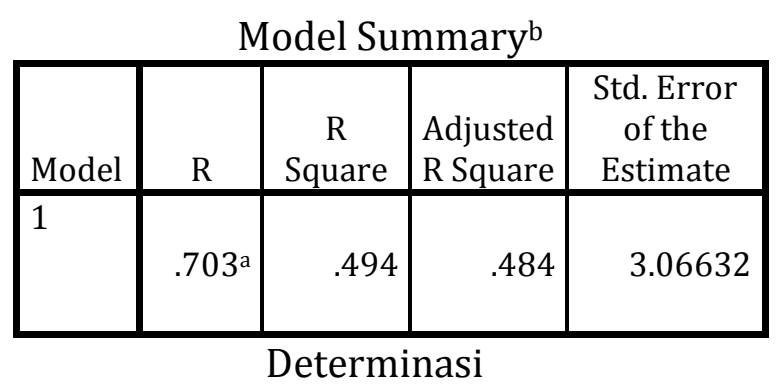

Dari Tabel 2 besarnya nilai koefesien determinasi atau Adjust R Square adalah 0,484 hal tersebut berarti $48 \%$ variabel minat masyarakat menggunakan tabungan iB Baitullah dapat dijelaskan oleh variabel promosi dan kualitas pelayanan. Sedangkan sisanya (100\%-48\%) adalah 52\% 
dijelaskan oleh variabel lain yang diluar persamaan diatas.

\section{KESIMPULAN DAN IMPLIKASI}

Berdasarkan hasil penelitian dan pembahasan yang telah diuraikan maka dapat disimpulkan bahwa: variabel promosi dan kualitas pelayanan secara parsial maupun secara simultan mempunyai pengaruh yang positif signifikan terhadap keputusan nasabah menggunakan tabungan iB Baitullah pada PT BNI Syariah KC Medan.

\section{DAFTAR PUSTAKA}

Al-Qur'an. 2010. Departemen Agama RI Al Qur'an dan Terjemahannya. Jakarta: Bintang Indonesia.

Anshori, Abdul Ghofur. Perbankan Syariah di Indonesia. Yogyakarta: Gadjah Mada University Press, 2009, hlm.92

Choliq, Abdul. 2013. Pengantar Manajemen. Semarang: Rafi Sarana Perkasa

Chotimah, Chusnul. 2014. "Pengaruh Produk, Layanan, Promosi dan Lokasi Terhadap Masyarakat Memilih Bank Syariah di Surakarta". Skripsi. Fakultas Ekonomi dan Bisnis. Universitas Muhammadiyah Surakarta

Daulay, Raihanah. 2014. "Pengaruh Kualitas Pelayanan dan Bagi Hasil Terhadap Keputusan Menabung Pada Bank Mandiri Syariah di Kota Medan". Jurnal Riset Akuntasi dan Bisnis.

Fajriyah, Neneng. 2013. Pengaruh Promosi, Reputasi dan lokasi strategis terhadap keputusan nasabah menggunakan produk Tabungan Haji
Mandiri KCP Tangerang Bintaro. Skripsi. Universitas Islam Negeri Syarif Hidayatullah.

Ghozali, Imam. 2017. Aplikasi Analisis Multivariete Dengan Program IBM SPSS 23. Semarang: Badan Penerbit Universitas Diponegoro.

Ismail. 2011. Manajemen Perbankan. Cetakan Kedua. Jakarta: Kencana.

Kotler, Philip. 2002. Manajemen Pemasaran Analisis Perencanaan Implementasi dan Kontrol. Jilid I. Prenhallindo: Jakarta.

Kotler, Philip dan Kevin Lane Keller, 2008. Manajemen Pemasaran. Jakarta: Erlangga.

Maski, G. 2010. "Analisis Keputusan Nasabah Menabung: Pendekatan Komponen dan Model Logistik Studi Pada Bank Syariah di Malang". Journal of Indonesian Applied Economics. Volume 4 Nomor 1 Mei 2010, 43-57.

Mubarokati, Maulana. 2017. Analisis Kualitas Pelayanan Dan Tingkat Kepuasan Nasabah PT Bank Bni Syariah Cabang Medan Dengan Metode Servqual. Skripsi. Fakultas Ekonomi Bisnis Islam. Universitas Islam Sumatera Utara

Muhammad. 2004. Manajemen Dana Bank Syariah. Yogyakarta: Ekonisia

Sugiyono. 2010. Metode Penelitian Pendidikan Pendekatan Kuantitatif, Kualitatif, dan R\&D. Bandung: Alfabeta. 
Sunyoto, Danang. 2015. Strategi Pemasaran. Yogyakarta: CAPS.

Sutisna, 2011. Perilaku Konsumen dan Komunikasi Pemasaran. Remaja. Bandung: Rosadakarya

Tajudin, M.H. 2017. "Pengaruh Promosi, Kepercayaan dan Kesadaran Merek Terhadap Keputusan Nasabah Menggunakan Produk Tabungan Haji di Bank Syariah Mandiri KCP Sawangan". Skripsi. Universitas Islam Negeri Syarif Hidayatullah Jakarta.

Tim Redaksi KBBI PB. 2008. Kamus Besar Bahasa Indonesia (Edisi Keempat). Jakarta: Pusat Bahasa Departemen Pendidikan Nasional.

Tjiptono, Fandy dan Chandra. 2005. Service, Quality, Satisfaction. Yogyakarta: ANDI.

Yogiarto, A.H.P. 2015. Pengaruh Promosi, Bagi Hasil dan Kualitas Pelayanan Terhadap Keputusan Penggunaan Jasa Perbankan Syariah Tabungan Mudharabah (Studi Kasus pada Nasabah Bank Muamalat Pekalongan).
Skripsi. Universitas Negeri Yogyakarta

http://ariefabian.blogspot.com/2011/07/ makna-dari-logo-bni-46yangbaru.html. Diunduh tanggal 31 Agustus 2019. Pukul 14.05 WIB

http://www.bni.co.id/TentangBNI/VisiMisi tabid/idd/Default. Diunduh tanggal 30 Agustus 2019. Pukul 17.07 WIB

www.bnisyariah.co.id. Diunduh tanggal 31 Agustus 2019. Pukul 13.44 WIB

www.bnisyariah.co.id/id-

id/personal/pendanaan/bnibaitullahi bhasanah. Diunduh tanggal 12 Juli 2019. Pukul 19.50 WIB

www.bnisyariah.co.id/idid/perusahaan/hu bunganinvestor/laporanpresentasi/la porantahunan. Diunduh tanggal 30 Agustus 2019. Pukul 16.56 WIB

www.harianhaluan.com/detailberita/5494 3/bni-syariah-raih-the-bestindonesia- digital-popular-brand. Diunduh tanggal 14 Juli 2019. Pukul $\underline{20.30}$ WIB 